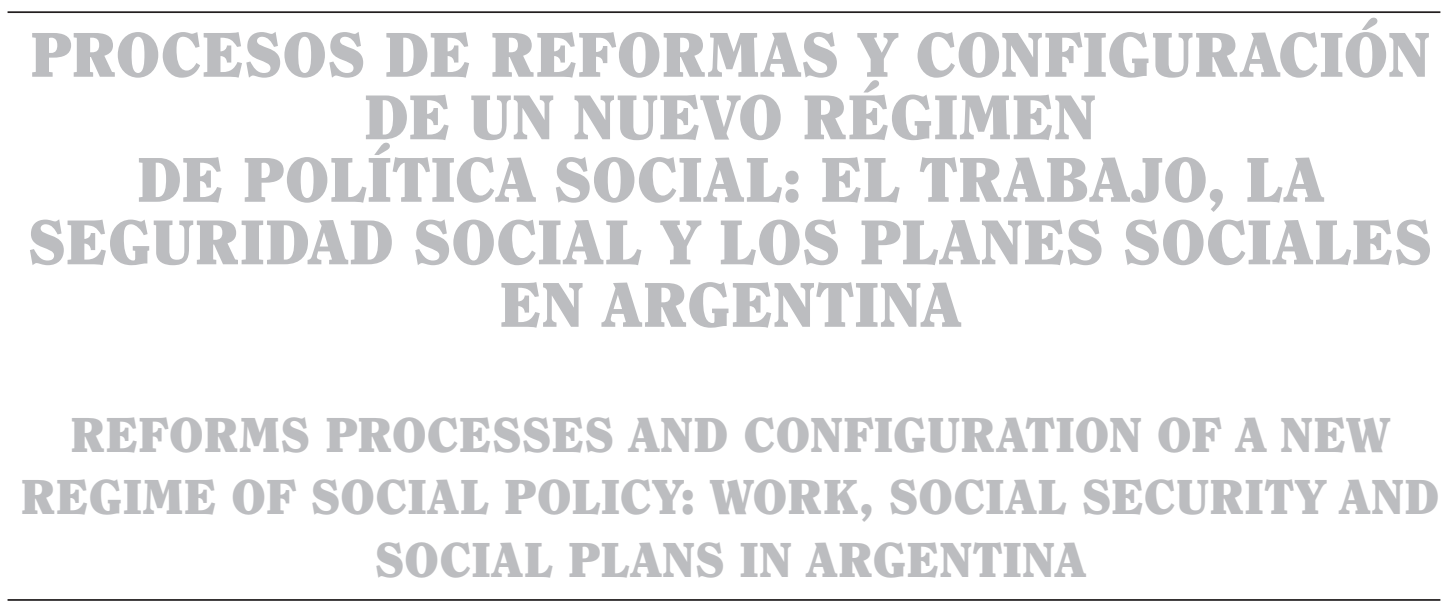

\title{
LA OTRA DÉCADA DE REFORMAS DE LAS POLÍTICAS SOCIALES Y LABORALES. ARGENTINA, 2002-2010
}

\section{THE OTHER DECADE OF REFORMS IN THE SOCIAL AND LABOR POLICIES. ARGENTINA, 2002-2010}

\section{Claudia Danani*}

\author{
RESUMEN
}

El artículo afirma que en 2003, se inició en la Argentina un proceso de contra-reforma de las políticas sociales de orientación neoliberal llevadas adelante durante los años 90 . Se analiza ese proceso deteniéndose en los contenidos político-culturales del mismo, en dos casos específicos: la política laboral y la previsional, contextualizándolo en la tradicional confrontación peronismo-antiperonismo. El artículo concluye que los núcleos de disputas más intensas refieren a los proyectos políticos globales que cada sector imputa a sus opositores y menos a los contenidos de las políticas en sí mismas, lo que da lugar a debates de fuerte sentido ideológico.

PALABRAS CLAVE: PERONISMO * ANTIPERONISMO * POLÍTICA LABORAL * POLÍTICA PREVISIONAL * CONTRA-REFORMA * LUCHA IDEOLÓGICA

Facultad de Ciencias Sociales de la Universidad de Buenos Aires, Argentina y del Instituto del Conurbano de la Universidad Nacional de General Sarmiento, Argentina. cdanani@sociales.uba.ar 


\section{ABSTRACT}

The article asserts that in 2003, Argentina began a counter-reform of social policies oriented to neoliberalism during the ' $90 \mathrm{~s}$. This process is analyzed stressing political and cultural contents for two specific sectors (labor and retirement policies) and contextualizing it in the traditional confrontation between peronism and anti-peronism. The conclusion is that the cores of disputes are not on contents of social and labor policies themselves but on global political projects and intentions put by each political sector down to their opositor. A deep ideological fight is the result from this process.

\section{KEYWORDS: PERONISM * ANTI-PERONISM * LABOUR POLICY * RETIREMENT POLICY * COUNTER-REFORM * IDEOLOGICAL FIGHT}

“A la pregunta ¿đónde está la oligarquia?’ formulada por La Nación hacía poco tiempo, es imaginable que muchos peronistas hubieran respondido: 'detrás de los grandes diarios"”

Sidicaro (1993: 202)

"El largo brazo del Estado hizo que todo sucediera a la vez y rápidamente, el incremento del número de asalariados, el desarrollo del sindicalismo, la redistribución de los ingresos y los bienes públicos y, en un nivel más profundo, la crisis de la deferencia y del respeto que el orden social preexistente acostumbraba esperar de sus estratos más bajos.

Por otro lado, lo que volvía todavía más difícil la asimilación del cambio era el tono desafiante con el que eran introducidas sus novedades. El programa de reformas sociales adquiría a través del discurso oficial los contornos épicos de una reparación histórica de incierto y por ello mismo inquietante desenlace. Si para entrever sus alcances la respuesta se buscaba en el lenguaje poco conciliador que Perón y sobre todo Evita utilizaban para dirigirse a los vencidos de 1946, entonces los peores presentimientos eran verosímiles. Para adivinar que detrás de tanta hostilidad existía un respeto no menos sincero por los fundamentos últimos del orden económico y social que criticaban, habría sido necesario contar con una serenidad de espíritu que pocos pudieron permitirse, envueltos como estaban en un clima de beligerancia y rechazo mutuo. Aunque el blanco de los ataques oficiales lo constituian las clases altas - esa multiforme y omnipresente oligarquía de la tradición política nacional-, las clases medias más antiguas se sintieron igualmente implicadas en la defensa de unos equilibrios sociales y políticos amenazados" Torre y Pastoriza (2004: 308-309)

\section{INTRODUCCIÓN}

En este artículo se analiza una parte de las políticas laborales $y$ de la seguridad social desarrolladas en la Argentina durante la primera década del siglo XXI, dos sectores de políticas -el laboral y el de la seguridad social- que durante el ciclo de hegemonía neoliberal estuvieron en el centro de las transformaciones de ese signo. Como se justificará en el desarrollo del artículo, se entiende que durante el período que aquí se estudia, en la Argentina, viene teniendo lugar un proceso que denomino de "contra-reforma" de ciertos sectores de políticas sociales, proceso que es intensamente problematizado en el debate social y político. Los contenidos político-culturales de esos debates -medio y resultado de los mismos - serán materia principal del análisis. 
En ese marco, el recurso a las dos citas introductorias (extensa una de ellas, como el lector ha podido ver) tiene por propósito proporcionar algo, así como, un telón de fondo sobre el cual los argumentos, posiciones y propuestas cobran sentido en el debate político y social argentino, debate que desde la década del 40 del siglo XX, se recorta sobre la confrontación peronismo-anti-peronismo (y si no siempre se recorta sobre ella, de todos modos nunca puede ignorarla). Así, en este artículo se pretende reconstruir las intervenciones sociales en marcha en la Argentina, durante la primera década del siglo, a partir de concebirlas como vehículos y manifestaciones de las luchas político-culturales que caracterizan al período; a la vez se presta atención especial a aquellos momentos en los que el desarrollo de estas intervenciones se cruza con el enfrentamiento peronismo-antiperonismo.

No es que ese enfrentamiento sea el eje central del análisis, pero advierto sobre su presencia cuando creo estar reencontrándome con él. El propósito de esa vigilancia es recordar algunos de los contenidos que históricamente albergó ( $y$ alberga, según se postula) la "excluyente cultura política argentina" (Spinelli, 2004: 609), con su eterna "mutua denegación de legitimidad", según las palabras acuñadas por Terán (2010: 250); y se hace con espíritu que no es de coleccionista, sino para señalar su vitalidad y recurrencia, además de la intensidad con que subyacen al proceso social, político-cultural e institucional que se analizará a continuación. Conforman, así, "estructuras de inteligibilidad" y de disputa de la vida política, en las que anidan importantes claves del presente (Svampa, 2011: 28) ${ }^{1}$.

Bajo el entendido de que toda intervención del Estado (y las intervenciones sociales entre ellas) son medio y resultado, al mismo tiempo, de una pugna por la dirección del

1 De allí la fuerza que se atribuye a las citas que encabezan el trabajo. Es oportuno agregar que María E. Spinelli (una especialista de cita obligada en lo que refiere a estudios sobre el AntiPeronismo) ensaya algunas interpretaciones acerca de por qué es tan dispar el interés que despertó el anti-peronismo respecto del que atrajo ( $y$ atrae) el peronismo (2005).
Estado $-y$ por lo tanto, de la sociedad-, la materia principal del análisis serán los temas (su selección, formas de definición y valoración) sobre los que se ha venido disputando en los debates políticos de los que dichas intervenciones sociales participan. Retomando palabras de Hintze (2006), en este caso se entiende a esas problematizaciones como parte de la evolución de las políticas que se analizan y de su "práctica real", en la medida en que hacen parte del escenario de la lucha social y política, de las orientaciones que la misma asume y de los cursos de acción que entonces, se convierten en posibles (un atributo que siempre requiere ser situado históricamente).

Como se dijo al inicio, para ello se concentrará en dos sectores de políticas en los que se entiende que ese proceso alcanza suficiente densidad social, política y cultural como para considerarlos un punto de observación, desde el cual desplegar un análisis de la institucionalidad y de las bases sociales legadas por la transformación neoliberal. Se trata de la política laboral y del sistema previsional que son, asimismo, dos sectores con peso propio en lo que hace a la reorientación del Estado.

\section{LA CONTRA-REFORMA COMO CLAVE ANALÍTICA, HISTÓRICA Y POLÍTICA}

Aunque hay variaciones en la jerarquización o los énfasis dados por los autores, el proceso de "reforma" de las políticas sociales llevado adelante durante el período de hegemonía neoliberal, es objeto de caracterizaciones relativamente compartidas; así, ese proceso suele describirse en términos de lo que Oszlak (2000) denomina una "reducción del perfil social y económico-empresarial del aparato estatal", lo que se expresa en orientaciones hacia la privatización, la participación, la descentralización y la focalización (Chiara y Di Virgilio, 2005); agregándose a la descentralización, la desconcentración y la tercerización (Soldano y Andrenacci, 2006; Fernández, 2001). Los rasgos compartidos alcanzan a las descripciones referidas a estudios regionales (hacia América Latina); tal es el caso del esquema ofrecido por Filgueira y otros (2006), quienes subrayan los ejes de la descentralización y privatización, 
de los que habrían derivado la focalización, el recorte en las responsabilidades del Estado, la mercantilización y los esquemas "matriciales" (reemplazo de políticas públicas por proyectos).

En este artículo se utiliza la expresión "contra-reforma" para aludir a un proceso de producción de políticas estatales en su doble dimensión de realidad inmediatamente material —vale decir, de producción de acciones $y$ omisiones directamente observables $-y$ de producción de sentido, que en esa combinación tienen en común dos elementos: a) el hecho de participar de un proceso en el curso del cual primero se detuvo y luego, de diversos modos y con distintos alcances, se invirtió la dirección que las políticas de ese mismo sector habían presentado en los años 90; es decir, en el período inmediatamente anterior al de este estudio; $y$ b) comparten también ciertas bases 0 fundamentos generales, dicho esto en el sentido de que, atribuyendo contenidos negativos a las políticas del ciclo previo, fundan y disputan su legitimidad en la operación misma de la diferenciación y confrontación con aquel período.

Esta es, entonces, la definición general de "contra-reforma" que aquí se propone y que se utilizará en adelante. En lo que es el período 2001-2010, el cual es el que se estudia, se completa el marco inicial señalando que en este trabajo se incluye empíricamente bajo esta denominación a un cierto conjunto de políticas que de manera explícita, encarnan el juicio negativo del ciclo histórico de hegemonía neoliberal, al postular la conveniencia práctica y la superioridad política y moral de intervenciones, que contradigan la dirección de instituciones y políticas desarrolladas en aquel período.

En esta propuesta, el recurso al concepto de contra-reforma como dispositivo analítico impone la consideración de ambas dimensiones. Dicho de otro modo, se concibe a la contrareforma como un proceso político-institucional (en tanto orienta materialmente las políticas), simultánea y explícitamente cultural, en tanto, le es intrínseco traer a la luz y someter a debate los contenidos políticos de los que está hecho. En tal sentido, no se trata de una corrección o re-diseño de políticas, sino de un declarado cambio de orientación de las mismas; al mismo tiempo, ello incluye la enunciación de otros intereses por cuya realización y legitimidad se pugna, fundando la construcción de los criterios y principios de esa legitimidad. Entiéndase, entonces, que se apela al concepto de contrareforma para dar cuenta de una disputa en el plano del "hacer políticas", lo que significa que no ha de inscribirse en un proceso de pura crítica especulativa. Con esto último no se desprecia la importancia de esa crítica, si fuera el caso - especialmente en cuanto hiciera parte del debate colectivo- sino que se procura rescatar la que es la dimensión inmediatamente pragmática del proceso.

Se sostiene que la mirada en clave de contra-reforma puede servir como punto de partida para emprender un examen imprescindible, el de: cuál es la sociedad y el Estado, que en sentido político-institucional y cultural, han quedado al cabo de la fabulosa transformación resultante de la hegemonía neoliberal ${ }^{2}$. Al proponer ese examen se pretende interponer una coartada a dos errores que se han hecho demasiado frecuentes (refiriéndose a los especialistas argentinos, al menos): repetir la denuncia de las perversidades del neoliberalismo y abordarlo, de hecho, con cierta ajenidad, como si se hubiera tratado de un proceso del que nuestras sociedades fueron víctimas, heroicas, en algunos casos; indefensas y/o pasivas, en otros. En cambio, preguntas tales como ¿cuál es el estado de ideas, valores y sentidos socialmente disponibles que ha quedado al cabo del proceso de hegemonía neoliberal? a su sombra, ¿es observable/posible un proceso de contrareforma? obligan a pensar en clave de la producción social resultante ( $y$ no de lo arrebatado o destruido), de las bases sociales sobre las que se erige la sociabilidad $y$ de aquellas que, por tanto, se requieren para su transformación. Por caso, al ocuparse de las formas de pensar la relación entre "sistema económico" y "sistema de políticas sociales", hace unos años Rubén Lo Vuolo (2006) trajo a la discusión una proposición perturbadora: que una característica de América Latina respecto a la política económica es que la credibilidad de esta (concebida como

2 Se retoma acá la pregunta que en 2008 hizo Estela Grassi. 
asentimiento y conformidad) está condicionada por una exigencia colectiva de suficiente desigualdad social. Dicho de otro modo, afirmó que las sociedades latinoamericanas exigen a la política económica que siga un patrón de desigualdad que acompañe $-y$ no, que contradiga- la fuerte desigualdad que caracteriza a la región; de lo contrario, se desconfiará de su capacidad de proveer orden. Desconfianza, agrego, que es ella misma fuente (y no automático resultado) de ineficacia. Quizás esté de más decirlo, pero prefiero correr el riesgo: las derivas de aceptar esa hipótesis son íntegramente diferentes a las de suponer sociedades relativamente abiertas $y$ con aspiraciones medianamente igualitarias $y$ tiene implicancias en el tipo y magnitud de protección social esperable y en los agentes a los que se considere legítimamente demandados. Tiene implicancias, en definitiva, en el Estado que se construya, asunto en el que se pretende internarme en lo que sigue.

Los cambios de décadas, más aún, si acompasan un cambio de siglo, suelen estar rodeados de cierto halo mágico. Más allá de ello, en este caso es conveniente advertir que en la Argentina, el pasaje coincidió con lo que fue la mayor y más traumática crisis socioeconómica y política que atravesó el país en su "historia moderna". Esa crisis se desató en diciembre de 2001 y tuvo un punto de estabilización en mayo de 2003, con un proceso electoral de renovación presidencial de resultas del cual se inició una gestión auto-identificada como peronista, que ha venido enunciando claras líneas de confrontación con las políticas que caracterizaron la década anterior ${ }^{3}$.

3 Para facilitar al lector la ubicación en el proceso, se dirá que "el ciclo de reforma o hegemonía neoliberal" corresponde en la Argentina a las dos presidencias consecutivas de Carlos Menem (Partido Justicialista — peronista—, 1989-1995 y 1995-1999). En octubre de 1999, ganó las elecciones una coalición autodenominada de "centroizquierda", así llamada "Alianza por el Trabajo, la Educación y la Justicia". La crisis desatada en diciembre de 2001 (con tasas de desocupación y pobreza cercanas al $50 \%$ de la población económicamente activa $y$ de la población total, respectivamente, virtual parálisis de la actividad económica y default de la deuda externa), arrastró tras de sí a cinco presidentes, sucesivamente elegidos por
LAS POLÍTICAS LABORALES: CONTENIDOS Y CONDICIONES DE LA REFORMA, PROCESO Y DEBATE

En el plano de las políticas laborales, la primera acción con la cual poner a prueba el concepto de contra-reforma es la derogación de la Ley 25250 de 2000, votada por el Congreso Nacional en marzo de 2004. Cabe una aclaración: en el artículo de Grassi de este mismo número puede constatarse que ya desde el pico de la crisis se habían tomado medidas de carácter contrario a las de la década del 90 (políticas de ingresos, de protección ante el despido, de subsidio al empleo), pero el hecho de haber sido tomadas en un momento transicional hace que pueda vérselas prioritariamente como "compensatorias" o "reparatorias" y por ello, más esquivas a formar parte de un "tipo" como el que aquí se presenta.

En cambio, la Ley 25250 en sí misma, había marcado una época durante el Gobierno de la "Alianza" (ver nota 3), tanto por sus contenidos como por el proceso político-institucional de su sanción. Por los primeros, porque mediante la misma, prácticamente se había formalizado el "régimen de precariedad" (Palomino, 2007) propia de la política laboral de los 90 (ampliación del "período de prueba", disminución de contribuciones patronales, ampliación de facultades de cese de relación laboral por parte del empleador, etc.) y por el segundo (el proceso político-institucional de sanción de la ley), porque el mismo estuvo envuelto en un escándalo que involucró al Poder Ejecutivo $y$ a legisladores de diferentes bancadas, acusados de haber cobrado "recompensas" por su voto favorable. Por todo ello, la derogación de esta ley, ocurrida en marzo de 2004, adquirió

la Asamblea Legislativa. En elecciones abiertas, en mayo de 2003, resultó elegido Presidente de la Nación Néstor Kirchner, representante del Partido Justicialista (para un sintético y a la vez, denso análisis de las distintas dimensiones de ese proceso, ver Hintze (2006), especialmente los capítulos 1 a 3). En la elección de la renovación presidencial de 2007, por la misma coalición política resultó electa Cristina Fernández (entonces Senadora Nacional y esposa del anterior), que en los días de redacción final de este artículo se presentó a la reelección, la cual ganó con amplio margen. 
carácter simbólico: se trató del primer proyecto enviado por el Poder Ejecutivo en sesiones ordinarias y obtuvo un apoyo de casi el 90\% (mientras los votos negativos correspondieron mayoritariamente a legisladores de izquierda y centroizquierda, que reclamaban a la norma mayor radicalidad). Todo ello pretendía marcar con claridad que comenzaba una nueva etapa.

No obstante, aún teniendo en cuenta ese carácter contra-reformador que bajo la forma de "reparación" institucional y normativa, asumió esta derogación, se entiende que la nueva Ley (25 877/2004), albergó desde entonces otra política, aún más contundente en términos de contra-reforma: la reconstrucción/recreación del Sistema de Inspecciones del Trabajo y la Seguridad Social, Instituto Central para el "Plan Nacional de Regularización del Trabajo" (PNRT), cuyo centro de acción es el combate contra las formas ilegales (y las legalizadas) del trabajo precario; asunto que se considera central y del que se ocupará en particular respecto de las políticas laborales. Este plan fue anunciado por el entonces Presidente Kirchner, en compañía del Ministro de Trabajo, Carlos Tomada, en agosto de 2003 y desde entonces funcionó con una institucionalidad transitoria hasta marzo de 2004, cuando la sanción de la Ley 25877 creó formalmente la que sería la definitiva.

El PNRT se presenta como una política activa de inspección de las condiciones laborales $y$ enuncia una serie de acciones, principalmente de fiscalización, que tienden a captar situaciones de trabajo no registrado ("trabajo en negro"), a fin de obligar su regularización y a que los trabajadores sean incluidos en los sistemas de protección, tanto los inmediatamente laborales como los de prestaciones sociales. Desde diciembre de 2003, atravesó tres etapas (en tiempos de redacción de este trabajo se encuentra en curso la tercera): a) Primera etapa, de diciembre 2003 a abril-mayo 2005, con acciones de relevamiento $y$ énfasis en lo informativo (campañas de disuasión para trabajadores y empleadores en condiciones de fraude o irregularidad laboral, que son denominadas "campañas de difusión y concientización”; rediseño de procesos con orientación a la facilitación administrativa, etc.); b) Segunda etapa, de abril-mayo 2005 a diciembre 2007: las acciones pasaron a etapa administrativa, en la que se ejecutaron las inspecciones y se labraron actas, imponiéndose las penas que marca la legislación; c) Tercera etapa, de enero 2011 al momento de redacción de este artículo: asociada a la incorporación de equipamiento para la mejor detección de casos de trabajo no registrado, en particular, por su contratación en contextos menos accesibles o más favorables a la elusión y evasión (v.g., áreas rurales) $)^{4}$.

Se sostiene que el PNRT es la política laboral más importante del Gobierno Nacional en el período analizado, como así también, es la que adquiere más claros contenidos de contra-reforma. Esta afirmación se basa en dos razones:

a) Este plan se instala en el centro mismo de la concepción de-socializada del trabajo y del empleo que organizó las políticas, las instituciones, las relaciones y las prácticas laborales de la década de 1990, que precisamente habían fundado el mencionado "régimen de precariedad" en el re-envío de las relaciones y el contrato de trabajo a la esfera de las relaciones entre particulares. En este sentido, el plan puede ser concebido como una acción articulada de re-fundación integral de las relaciones laborales, afirmación que incluye el cultivo de una racionalidad contraria a la que orientó las políticas de los años 90. Cabe aclarar que durante ese período, se libró una batalla contra el trabajo en negro, sí; pero la misma asumió una doble vía: para los trabajadores, la auto-registración impositiva para el desempeño de "consultorías", "asesorías", "locaciones

$4 \quad$ En esta tercera etapa se ha sospechado $-y$ sigue estándolo- de entremezclar el afán de inspección con ejercer presión sobre los propietarios rurales (especialmente, los grandes propietarios), con los cuales el Gobierno Nacional mantiene un conflicto sociopolítico y económico que lo arrastró a una severa crisis entre marzo y julio de 2008 . 
de servicios" varios, etc. ${ }^{5}$, lo que en el plano de la protección contra riesgos se concretaba en la auto-protección de mercado (por adhesión obligatoria a sistemas de capitalización individualizados como los de jubilaciones y seguro de salud, por ejemplo) y por lo tanto, en la auto-responsabilidad. Para las empresas, la "obligación” de controlar la efectivización de los aportes de las personas contratadas bajo las condiciones mencionadas (lo que implicaba certificar la condición no laboral de la relación y en cambio, afirmar su condición "puramente" mercantil), a lo que se sumaba una retórica que argumentaba sobre las desventajas del "empleo no registrado" asumiendo explícitamente el punto de vista del capital ${ }^{6}$. Evidentemente, en esa conceptualización, no hay lugar para un enfoque de derechos; respecto a lo cual, en cambio, el PNRT produce un giro: invoca el cumplimiento de "los derechos fundamentales del trabajo" y la necesidad de "la debida protección social", anudando "contralor de la no registración con calidad del trabajo" (Jefatura de Gabinete de Ministros, 2003: 16) ${ }^{7}$.

Proceso en el cual el sector público fue vanguardia de la disolución de la relación laboral (Lindenboim, 2003: 80).

"Quien incumple normas laborales gana competitividad en forma espuria [y] limita la capacidad de desarrollo", decían en 2003 ex-funcionarios de los equipos económicos y laborales del Gobierno de Carlos Menem. Y agregaban: "Tener empleados no registrados implica operar con un pasivo contingente elevado e incierto ya que la empresa está permanentemente expuesta al quebranto que le puede ocasionar un juicio laboral. (...) La contratación de empleados sin cumplir las normas puede formar parte de una estrategia de sobrevivencia o una acción transitoria de muy corto plazo, pero es incompatible con una estrategia sustentable de crecimiento y desarrollo de la empresa" (Giordano, Colina y Torres, 2003: 5).

Pautassi (2010a y b) presenta la idea de políticas públicas inspiradas en un enfoque de derechos, así como, un análisis de los avances y límites de las políticas desarrolladas en la Argentina entre 2003 y 2010. b) En vinculación con lo anterior, el PNRT disputa la legitimidad del control estatal de las relaciones laborales, reconstruyendo la institución de la inspección y sanción en las unidades económicas (y no principalmente en los individuos, como en el período anterior) y argumentando acerca de la pertinencia de la acción estatal directa ${ }^{8}$. En conjunto, entonces, ha invertido el sentido de la política laboral de aquellos años, lo que resulta estratégico, en tanto la transformación del trabajo $y$ de las condiciones sociales de su realización había representado la clave de aquel otro cambio de época. En el período al que aquí me refiero, el PNRT hace de la explicitación de sus contenidos y de la capacidad de imposición de significados, el eje de lo que se torna, así, una disputa plena por una nueva visión y horizonte social y por supuesto, por su dirección. Es decir, por la hegemonía (Cortés y Marshall, 1999; Danani y Lindenboim, 2003; Grassi, 2003 y 2008; Palomino, 2007; entre otros).

Al proponerse este punto de vista como clave de lectura, se continúa con dos notas de muy distinto orden- sobre cuestiones que a juicio propio hacen al asunto, para luego examinar algunas derivaciones.

La primera es, en cierto sentido, algo inquietante $y$ es que en lo que hace directamente al PNRT, debe decirse que es una política que tiene solo relativa - por no decir escasa - visibilidad pública (política), por debajo de lo que podría esperarse en virtud de su importancia. Esto a partir del hecho de que este plan no ha alcanzado satisfactoria difusión y estado de debate social; en síntesis, no circula, no moviliza discusiones. Al respecto, por ejemplo, la campaña por la regularización del personal doméstico

$8 \quad$ "Si bien los empleadores tienen la obligación de declarar y registrar a los trabajadores es el Estado, mediante este plan, quien pone en práctica su rol de contralor de la normativa laboral y de la seguridad social, verificando su cumplimiento, logrando así la registración plena de los trabajadores..." (MTEySS, en: <http://www.trabajo.gov.ar/inspeccion/pnrt>. Consultado 23 de marzo de 2011). 
ha sido mucho más efectiva, si bien es cierto, que por la naturaleza de esta última campaña - el hecho de traer a la luz situaciones que ocurren puertas adentro de los hogares-, la difusión debe ser más intensa y a la vez, cientos de miles de hogares están comprometidos. También es cierto que, a la hora de debatir, el carácter ilegal del trabajo no registrado plantea un terreno difícil de transitar para quienes se opongan (¿cómo argumentar a favor de la violación de la ley?); pero, aún así, la cuestión requiere ser considerada.

A juicio propio, esto intersecta de manera sui generis con la polémica peronismo-antiperonismo de la que se habló al principio. Me refiero a que la discusión y la crítica de las políticas -en tal caso, del gobierno por parte de la oposición- a menudo han versado más sobre "los procesos sociopolíticos" o "la dinámica social" asociadas a las políticas o instituciones estatales, que sobre los contenidos de esas políticas en sí mismos. Se cree que eso ha sucedido con algunas políticas laborales. Así, a partir de 2005, fueron aumentando sensiblemente las manifestaciones de disconformidad expresadas por el diario La Nación, por los episodios de protesta social (en el presente identificada con la figura del "piquete"): "Más sectores recurren al piquete", "El retorno de los piquetes" o "[La ciudad de] Resistencia quedó aislada por marcha de desocupados", son solo algunos de los titulares, pero para el objetivo que se propuso en este artículo cobran importancia porque se engarzan en una línea editorial que, en primer lugar, cultiva la interpretación de que dicha protesta es resultado del aliento gubernamental. Ello puede verse en otros titulares o expresiones: "Kirchner alentó la discusión salarial" (2/2/2007) o "Para algunos, el cambio fue sumarse al poder, transformarse en fuerzas movilizadas en la calle al servicio del Gobierno y esperar recompensas políticas" (29/7/2007). Un segundo eje por el que se cree que esta crítica desborda la política presente y a la vez, se ubica en una línea de continuidad que no repite, sino que resignifica y recrea posturas $y$ condiciones del debate, es lo descripto por Sidicaro (1993) para el período 1943-1947. En efecto, dice el autor que en los años previos a la asunción de la primera Presidencia de Perón, el mismo diario La Nación había aceptado que ciertos conflictos en el mundo del trabajo eran parcialmente justificados dadas las bajas remuneraciones "... o el incumplimiento de las reglamentaciones, pero esta perspectiva no le parecía adecuada en 1946 [cuando Perón asumiera la Presidencia], con los niveles salariales mejorados y el gobierno $y$ los sindicatos haciendo respetar las normas laborales" (1993: 200). Sirve reforzar la ilustración: aquella nota del 2/2/2007 en la que se sostenía que en ejercicio de la Presidencia, Néstor Kirchner había alentado los reclamos salariales, estuvo acompañada por un editorial cuya conclusión era que se producía "un regreso al clásico discurso peronista" ¿Cómo resistir, entonces, la búsqueda de las claves de un discurso anti-peronista, igualmente clásico? No sin cierta sorpresa, como ya se dijo, se encuentra entonces que las - a menudo violentas - discusiones sobre las políticas del gobierno nacional, se tejen en una trama cerrada con motivaciones atribuidas, sospecha de intereses ocultos y evocaciones históricas, y menos análisis y contra-propuestas sobre sus contenidos inmediatos que lo que sería esperable. No es que no exista discusión sobre esos contenidos inmediatos; pero es preciso prestar atención a la fortaleza de una confrontación que recrea su pasado y su actualidad de manera permanente, en buena medida, visceral, según la descripción que Ostuguy hace de las formas en que Peronismo y anti-Peronismo racionalizan sus respectivos discursos (1997: 37); con ello, cobran relativa independencia de los contenidos y orientación de las políticas (si se habla de la oposición) y de las críticas (si se habla del oficialismo).

Con esta segunda nota se vuelve a la "inmediata materialidad" de PNRT, para decir que nada de lo expuesto como avances, en términos de combate al trabajo precario, constituye sin más una evaluación positiva del plan como tal; antes bien, debe decirse que, en tanto política, es altamente perfectible, en especial en lo que refiere a la escala de las acciones. Alguna de la información disponible ayuda a la reflexión, si se mira la cuestión en términos de la proporción de precarios sobre el total de 
asalariados, se ve que en 2003 el 43,8\% de los asalariados no estaba registrado, situación en la que en 2010 revistaba el $36,4 \%$ del mismo grupo. Si en cambio se echa la mirada al número total de personas en esa condición, al inicio del período se trataba de 4100000 y en 2010, de 4600000 (CEPED, 2011) ${ }^{9}$. Estos números muestran dos fenómenos de idéntica importancia, pero pasibles de interpretaciones contrarias; por un lado, en términos proporcionales, se ve un claro freno al proceso de creación estructural de empleo precario (en la medida en que el $84 \%$ del empleo creado punta a punta fue de carácter protegido). Por otro lado, el hecho de que el número absoluto de precarios haya seguido creciendo, muestra que hay más que "restricciones" o "dificultades" para proteger el empleo que "nació" precario. Teniendo en cuenta que se trata de los siete años que los especialistas (cualquiera sea su orientación) consideran los históricamente más favorables de la economía argentina, puede pensarse bien que se está frente a una nueva base estructural de empleo precario sobre la que funcionaría el capitalismo argentino post-90; bien, ante una sociedad y unas políticas con altos niveles de tolerancia (cultural, institucional, social) a la precariedad y a la ilegalidad que ella implica.

En realidad, las respuestas no son excluyentes y para dar cuenta de las preocupaciones de este artículo respecto del legado de la hegemonía neoliberal, más bien puede pensarse en su confluencia. Ambas apuntan en la dirección de advertir que la resolución de problemas como el de la precariedad laboral demanda operativos de una masividad que no ha sido alcanzada en absoluto. Asimismo, tal como señaló Adriana Marshall, en ocasión de una presentación públi$\mathrm{ca}^{10}$, uno de los puntos más llamativos es la insuficiente movilización gremial como agente

$9 \quad$ Se trata de promedios anuales. Elaboración del CEPED sobre la base de la EPH, empalmada. Graña y Lavopa. Documento de Trabajo 11. 2008 y actualización.

10 Se trata de su comentario a la presentación de Luis Beccaria en el IV Foro del Bicentenario "Políticas Públicas para la reducción de la desigualdad", organizado por la Secretaría de Cultura de la Nación el 23 de setiembre de 2008 . Notas propias. de esta iniciativa, en particular, por el hecho de que se trata de un sector que dispone de condiciones comparativamente más favorables que otros para ejercer esas funciones. Sin embargo, eso parece haber ocurrido menos que limitadamente $y$ a ello hay que agregar el papel francamente precarizador, que por acción u omisión, juegan algunos sindicatos. Al respecto, - cómo negarlo- las políticas son menos contundentes. Dicho de otro modo: la denuncia (al menos, la de carácter político) referida a la precarización laboral apunta casi con exclusividad a las patronales $y$ es reticente a comprometer al sector gremial, aún cuando es sabido que aquel "régimen de precariedad" al que alude Palomino (2007) no habría sido posible sin un sistema sostenido en la colusión entre sectores patronales $y$ dirigencias sindicales de diversa escala ${ }^{11}$.

Como se evidencia, las relativizaciones posibles son muchas; pero aún así, el PNRT hace parte de un ciclo de mejoras de las condiciones de trabajo. La centralidad que se asigna a la transformación de estas últimas, bajo la hegemonía neoliberal, es lo que lleva a valorar el ciclo actual a la luz de lo acontecido con el trabajo precario, pero se debe reconocer que, aún cuando las mejoras puedan ser limitadas, no se han reducido a ese asunto. La creación de empleo y la recuperación de las remuneraciones son otras dos dimensiones del proceso. El avance de los niveles salariales - tema medular en cualquier contexto - fue importante, pero más lento que la mejora del empleo - nuevamente estamos frente a procesos que reclaman interpretaciones complejas-, al punto que recién en 2007, se alcanzaron los niveles salariales previos a la crisis de 2001-2002 (Beccaria, 2008). De allí en más, deben señalarse dos deudas de importancia: la primera, se relaciona con la necesidad de hacer lugar a una discusión

11 De hecho, en octubre de 2010, tuvo lugar en la Ciudad de Buenos Aires, un enfrentamiento entre grupos sindicales del sector ferroviario, de resultas del cual fue asesinado un joven huelguista participante de una protesta. El destinatario de la misma era otro grupo gremial, al amparo de cuya dirigencia una de las empresas concesionarias mantenía una prolongada estrategia de terciarización del personal. 
desprejuiciada sobre el papel que cumple la actividad paritaria en la situación de los asalariados, en la distribución del ingreso y en la constitución misma de una "clase trabajadora", aún con lo ambiguo que resulta esa expresión. Con esto se llama la atención sobre las brechas crecientes que, por sectores de actividad, se registran en términos salariales directos e indirectos, en las condiciones de trabajo, etc. Este asunto admite —o reclama, más bien - un debate acerca de qué políticas son necesarias para que las condiciones más favorables de algunos sectores reviertan colectivamente, en lugar de profundizar la segmentación social y económica que ha resultado de los últimos 30 años; claro que tales políticas no podrían referirse solamente a las propiamente estatales $y$ deben abarcar las acciones sindicales. En cuanto a la segunda deuda, finalmente, puede decirse que prácticamente nada de lo anterior puede ni podrá ser debidamente dimensionado sino se revierte la política gubernamental sobre el organismo oficial de producción de información estadística (Instituto Nacional de Estadísticas y Censos, INDEC), el cual desde principios de 2007, está siendo sometido a una acción de "intervención política" que está ocasionando una pérdida - a esta altura, irreparable - de orden informativo pero sobre todo, políticoinstitucional.

\section{LA POLÍTICA PREVISIONAL: UN CASO OPUESTO DE ALTA VISIBILIDAD Y POLÉMICA POLÍTICA}

De acuerdo con lo planteado en trabajos anteriores (Beccaria y Danani, 2009; Danani y Beccaria, 2011), entre 2004 y 2008, el gobierno argentino llevó adelante un "proceso de contra-reforma previsional" que alcanzó su punto culminante en noviembre de 2008. En efecto, mediante un proyecto presidencial enviado al Congreso Nacional, que en apenas un mes obtuvo una contundente mayoría legislativa, fueron eliminados el sistema de capitalización creado en 1993 y las Administradoras de Fondos de Pensiones (en adelante, AFJP) nacidas entonces; en consonancia, se re-estatizaron los fondos previsionales y se unificó el sistema en un único régimen de reparto (Sistema Integrado Previsional Argentino, SIPA).
A juicio personal, con esta reforma se desarrolla un proceso que es de los más nodales de este período, afirmación que apoyo en dos argumentos. El primero, es que en él resuena ese "largo brazo del Estado" del que hablan Torre y Pastoriza en la cita inicial, figura que funciona como factor de identidad de los 60 años de existencia del Peronismo. El segundo, es el carácter emblemático que en el marco de las políticas de "ajuste estructural" de la década de los 90, tuvo la "reforma previsional"; columna vertebral de ese ciclo en lo que a las políticas sociales refiere, el sistema previsional volvió a estar en primer lugar a la hora de presentar los balances en términos de condiciones de vida y (des)protección.

Bajo estas condiciones y con una intensidad propia de los períodos peronistas, desde 2003 se encuentra (rabiosamente) sometida a discusión la noción de "intervención e intervencionismo estatal", noción que todos aquellos que participan de la polémica pretenden refundar. Ahora bien, en este proceso, la disputa es mucho más intensa con respecto al sentido, que del significado de los términos, lo que tiende a favorecer un patrón de confrontación entre los elencos gubernamentales y la oposición -en especial la oposición mediática, más aún que la oposición política "clásica" - que adquiere características singulares; ni unos ni otros ocultan o niegan lo que su interlocutor denuncia, sino que pugnan por convertir en emblema lo que el otro sector imputa como estigma y viceversa.

Con ejemplos directos, los que se retomarán luego: la oposición imputa al gobierno el intervenir en los mercados, aumentar el gasto público y alentar las demandas de grupos de trabajadores, organizaciones sociales y sindicales, etc. $y$ el gobierno no niega la acusación sino que, por el contrario, se esfuerza por señalar las virtudes de esas políticas en términos de justicia y bienestar. A la inversa, el gobierno recrimina a la oposición, el estar interesada en bloquear la participación estatal en la economía, liberar la acción de los mercados y retacear las contribuciones de los sectores propietarios (el pago de impuestos). Al igual que en el caso anterior, todo ello es admitido y "defendido" 
por la oposición, con base en la superioridad moral y la eficiencia que, afirma, tiene un orden basado en la iniciativa, la capacidad de emprendimiento, la libertad de empresa y la justa retribución al esfuerzo.

Al ocuparse de lo que aquí se llama la "contra-reforma" previsional, se han seleccionado tres temas que, según se cree, organizan la discusión política sobre la reforma de las políticas sociales y en particular, del sistema de seguridad social. Ellos son: la modificación de la distribución del ingreso por cuenta de la acción estatal, el papel igualador atribuido a estas intervenciones $y$ el deber (o las virtudes) que, según sostiene el discurso oficial, tiene el Estado de proveer certezas y seguridades a las personas. Los tres estuvieron presentes en el mensaje con el cual el Poder Ejecutivo envió el proyecto de eliminación del sistema de capitalización y de creación del nuevo sistema de reparto, cumpliendo así, el papel de fundamentos directamente políticos de esa iniciativa. De tal modo, combinando los elementos sociales y "propiamente políticos" de la tradición peronista con sus contenidos, retórica y raíces socio-culturales, ese documento se convirtió en un testimonio que ratificaba los orígenes $y$ la identidad, al mismo tiempo, la actualizaba según las coordenadas de los enfrentamientos del momento.

La idea formulada por autores como James (1999) y el propio texto de Torre y Pastoriza de la cita inicial (2002) — según la cual la confrontación y el desafío son rasgos intrínsecos del Peronismo- goza de reconocimiento en los estudios sobre el tema. Por ello, lo que aquí más importa observar son los términos del enfrentamiento, pues es en ellos que la confrontación y el desafío se actualizan y conforman. Tal como con Alejandra Beccaria, se dijo en otro lugar, puede ensayarse la interpretación de que la fórmula "progresismo/neoliberalismo", que en la década que aquí se analiza, recorre las discusiones a un lado y a otro de mesas y tribunas, le permite al kirchnerismo actualizar históricamente y "re-presentar de manera doctrinariamente tolerable la más clásica dicotomía izquierda-derecha" (Danani y Beccaria, 2011: 133) ${ }^{12}$.

En este proceso, esa retórica vehiculiza y amasa dos contenidos específicos: el "estatismo" (el acusado y el defendido), que se expresa en mencionados de: la participación en la distribución del ingreso, en la reducción de la desigualdad y en la creación y/o expansión de los sistemas de protección, del mismo modo que en el PNRT reivindicaba el contralor estatal de la normativa laboral $y$ de la seguridad social; y "el trabajo como fuente de derechos", el otro núcleo temático que tiende la gran línea de continuidad con la "tradición peronista". La confluencia de ambos presenta a esta política como reparación de las consecuencias del neoliberalismo, esbozada como una moneda de dos caras: "hacia arriba", la recuperación y reconstrucción del Estado como institución realizadora de justicia; "hacia abajo" (la población), la protección misma como acto de justicia. Esto da sustento al análisis de Ostuguy sobre las alianzas sociales en las que se apoyara el Peronismo, cuando afirma que “... el núcleo de la base social del partido [Peronista] es, y permaneció, sólidamente vinculada al tercio socialmente inferior de la sociedad" (1997: 3), agregando que en la experiencia internacional no hay casos de asociaciones partido-sectores populares tan claras $y$ directas.

En torno a estos mismos contenidos específicos que organizan el debate, la oposición —como ya se dijo, especialmente la

12 En una entrevista contemporánea con la redacción de este artículo, Carlos Altamirano llama la atención sobre las espaciadas e indirectas alusiones que la coalición gobernante hace sobre los orígenes del Peronismo, afirmando que se detiene más en su sentido que en su historia como tal (dicho de otro modo, insiste más en la épica que en sus figuras, como Juan Perón y Eva Duarte). El espacio disponible no me permite profundizar en las consecuencias (en el plano de las prácticas sociopolíticas $y$ de identidad) vinculadas con esta renovada amalgama de tradición peronista y corrientes de izquierda, que se expresa en la disputa por el espacio del "progresismo". Svampa (2011) ofrece varias líneas sugerentes para internarse en la cuestión, en particular al ocuparse del punto de fusión entre los "nuevos" contenidos en los que el gobierno argentino hace énfasis y lo que llama la "exacerbación de los contenidos nacional-populares". 
oposición mediática- atribuye a la intervención del Estado en la distribución del ingreso, un papel distorsivo; al papel igualador que el Poder Ejecutivo declara promover, le achaca una acción confiscatoria y en la declaración del deber del Estado de proveer seguridades $y$ certezas, encuentra una fuente de ineficiencia. He aquí, entonces, la mencionada disputa sobre el sentido, en tanto, la misma se concentra en la valoración que se realiza: redistribuir para igualar $y$ proveer seguridad para proteger o atropellar el derecho a la propiedad provocando pobreza generalizada, siendo estos dos paradigmas de lectura e involucramiento. También este puede ser considerado un "contenido clásico" de una más larga tradición y condiciones de la lucha político-cultural en la Argentina, si se presta atención a Spinelli, cuando recuerda el reproche que una edición de Clarín hacía al Peronismo en 1956, por haber estimulado la idea de que “... sin un proporcionado esfuerzo y disciplina personal pueden obtenerse retribuciones extraordinarias" (2004: 628).

\section{(BÚSQUEDA DE) CONCLUSIONES}

En este artículo se presentan dos políticas estratégicas que, aunque por vías diferentes $y$ con marchas, contramarchas $y$ contradicciones, dan sentido al concepto de contra-reforma, que postulo, se abrió en la Argentina, en el año 2003.

Si se retoman las preguntas acerca de las bases sociales y políticas para la reversión del regresivo proceso atravesado por la Argentina, en los años 90, tres son los aspectos que, a juicio personal, deben ser considerados:

1. Argentina cuenta actualmente, con un sistema de relaciones laborales y un sistema previsional que protegen a más personas y que lo hacen - cuestión fundamental para el tipo de reflexión propuesto- declarando y defendiendo explícitamente las virtudes de las garantías de esa protección, como rasgos de una sociedad moderna. Esto constituye una plataforma radicalmente diferente de la legada por la transformación neoliberal, en cuyo marco, las demandas de protección y seguridad eran consideradas indicadores de fracaso o debilidad que debían ser superados.

2. Las formas de enfrentamiento alrededor de esta cuestión han sido diferentes en cada uno de los sectores que se analizó. Los ejes fundamentales del debate son compartidos, ya que en ambos se discute si el Estado es el eje de las relaciones e instituciones de cada uno de los sectores $y$ si es socialmente deseable o condenable, la promoción de mayor participación de las clases trabajadoras/sectores populares en los beneficios económicos y sociales. No obstante - y contra lo que podría esperarse a priori- la política previsional es la que disparó el mayor realineamiento. En efecto, "estatismo y mercadismo" - dos consignas detrás de las cuales se ve embanderarse a oficialismo y oposición, respectivamente- encontraron un lugar y punto de debate respecto a la reforma previsional, que ha tenido gran capacidad de aglutinar argumentos, disputas y alianzas.

3. La coalición gobernante en Argentina recrea de modo sui generis, la tradición del peronismo y lo mismo - a la inversa- hace la oposición con su propia tradición, la del antiPeronismo. Ello ocurre en un período particular para América Latina, región en la cual, bajo la denominación de "progresismo", las posiciones favorables a una mayor igualdad socio-económica han ganado relativo terreno. La peculiaridad del caso argentino quizás pueda identificarse en el carácter fundacional que unos y otros asignan a los proyectos políticos globales que atribuyen a sus contendientes. Así, puede afirmarse que esta "otra" década de reformas de las políticas laborales y sociales es una década de lucha ideológica en su más plena definición: una lucha - con luces y sombras - por las ideas que "deben" orientar y dirigir a la sociedad. Esta explicitación de los contenidos da lugar a algo así, como una (re)politización de las políticas; central para las intervenciones que se desarrollaron en este artículo, en tanto traen a la luz el carácter colectivo de las condiciones de vida. Bien mirado, este hecho mismo es parte de la contra-reforma.

\section{BIBLIOGRAFÍA}

Altamirano, Carlos. Peronismo y cultura de izquierda. Buenos Aires: Siglo XXI Editores, 2011. 
Cabrera, Claudia. "Empleo y seguridad. La experiencia de trabajar en negro". El mundo del trabajo y los caminos de la vida. Trabajar para vivir, vivir para trabajar. Grassi, Estela y Danani, C. (orgs.). Buenos Aires: Espacio Editorial, 2009.

Chiara, Magdalena y Di Virgilio, Mercedes. Gestión social y municipios. De los escritorios del Banco Mundial a los barrios del Gran Buenos Aires. Buenos Aires: UNGS/Prometeo, 2005.

Danani, Claudia y Beccaria, Alejandra. "La (contra)reforma previsional argentina 2004-2008: aspectos institucionales y político-culturales del proceso de transformación de la protección. Protecciones y desprotecciones. La seguridad social en la Argentina, 19902010. Danani, C. y Hintze, S. (coords.). UNGS, 2011.

Danani, Claudia y Lindenboim, Javier. "Trabajo, política y políticas sociales: ¿qué hay de particular en el caso argentino?". Entre el trabajo y la política. La reforma de las politicas sociales argentinas en perspectiva comparada. Buenos Aires: Biblos, 2003.

Fernández Soto, Silvia. "La intervención social del Estado en los noventa. Un análisis de la implementación del Plan Vida en la ciudad de Tandil (Provincia de Buenos Aires)". Congreso Nacional de Estudios del Trabajo. Pre-Congreso FCH-UNICEN. Tandil: ASET, 2001.

Filgueira, Fernando et ál. "Universalismo básico: una alternativa posible $y$ necesaria". Universalismo básico. Una nueva política social para América Latina. Molina, Carlos G. (ed.). México: BID/Planeta, 2006.

Grassi, Estela. Politica y problemas sociales en la sociedad neoliberal. La otra década infame I. Buenos Aires: Espacio Editorial, 2003.

Grassi, Estela. Politica y cultura en la sociedad neoliberal. La otra década infame II. Buenos Aires: Espacio Editorial, 2004.

Grassi, Estela. "Argentina. La reforma neoliberal y la ¿"contra reforma"?
Transformaciones estructurales y una larga transición". Seminario Internacional Dilemas latinoamericanos actuales de cara el desarrollo y la democracia. Mimeo. En prensa. Guadalajara. Cátedra Alain Touraine, ITESO.

Hintze, Susana. Politicas Sociales argentinas en el cambio de siglo. Conjeturas sobre lo posible. Buenos Aires: Espacio Editorial, 2006.

James, Daniel. Resistencia e integración. El peronismo y la clase trabajadora argentina, 1946-1976. Buenos Aires: Editorial Sudamericana, 2010.

Lindenboim, Javier. "El mercado de trabajo en la Argentina en la transición secular: cada vez menos y peores empleos". Entre el trabajo y la política. La reforma de las politicas sociales argentinas en perspectiva comparada. Buenos Aires: Biblos, 2003.

Lo Vuolo, Rubén. "La credibilidad social de la política económica en América Latina". La credibilidad social de la politica económica en América Latina. Lo Vuolo, R. (comp.). CIEPP/Miño y Dávila, 2006.

Pautassi, Laura. "El enfoque de derechos y la inclusión social. Una oportunidad para las políticas públicas". Perspectiva de derechos, políticas públicas e inclusión social. Debates actuales en la Argentina. Buenos Aires: Editorial Biblos, 2010a.

Pautassi, Laura. "Políticas y derechos. Escenarios posibles". Perspectiva de derechos, politicas públicas e inclusión social. Debates actuales en la Argentina. Buenos Aires: Editorial Biblos, 2010b.

Sidicaro, Ricardo. La política mirada desde arriba. Las ideas del diario La Nación, 1909-1989. Buenos Aires: Editorial Sudamericana, 1993.

Soldano, Daniela y Andrenacci, Luciano. "Aproximación a las teorías de la política social a partir del caso argentino". Problemas de política social en la Argentina Contemporánea. Andrenacci, L. (comp.). Buenos Aires. UNGS/ Prometeo, 2006: 17-79. 
Terán, Oscar. Historia de las ideas en la Argentina. Diez lecciones iniciales, 1810-1980. Buenos Aires: Siglo XXI Editores, 2010.

Torre, Juan C. y Pastoriza, Lilia. "La democratización del bienestar". Los años Peronistas (1943-1955). Torre, J.C. (dir.). Colección Nueva Historia Argentina. Buenos Aires: Editorial Sudamericana, 2002.

\section{REVISTAS}

Cortés, Rosalía y Marshall, Adriana. "Estrategia económica, instituciones y negociación política en la reforma social de los 90". Revista Desarrollo Económico 154. Buenos Aires: IDES, 1999.

Lindenboim, J.; Kennedy, D. y Graña, Juan. "El debate sobre la distribución funcional del ingreso". Revista Desarrollo Económico 196. Buenos Aires, 2010

Oszlak, Oscar. "El mito del estado mínimo. Una década de reforma estatal en Argentina". Revista Desarrollo Económico 168 (42). Buenos Aires. Enero-marzo 2003.

Spinelli, María. "La 'otra multitud'. Las movilizaciones antiperonistas durante la 'Libertadora'". Revista Desarrollo Económico 172. Instituto de Desarrollo Económico y Social. Enero-marzo 2004: 609-635.

Svampa, Maristella. "Argentina, una década después. Del 'que se vayan todos' a la exacerbación de lo nacional-popular". Revista Nueva Sociedad 235. Setiembreoctubre 2011: 17-34.

\section{TEXTOS ELECTRÓNICOS}

Giordano, O.; Colina, J. y Torres, A. "La masividad del empleo no registrado en la Argentina. Aprendiendo de los fracasos". Documento de discusión 1. Buenos Aires: IDESA, 2003. En: <http:// cdi.mecon.gov.ar/novedades/junio2004/ bibliograficas0604/trabajo0604.htm>

Graña, Juan y Lavopa, Alejandro. "15 años de EPH, una serie. Empalme entre sus versiones Puntual y Continua, 1992 2006". Documento de Trabajo 11. CEPED, 2008. En: <http://www.econ.uba. ar/www/institutos/economia/Ceped/ publicaciones.htm>

Ostiguy, Pierre. "Peronism and anti-peronism: social-cultural bases of political identity in Argentina". Congreso de LASA. Guadalajara, 1997. En: <lasa. international.pitt.edu/LASA97/ostiguy4. pdf $>$

OTROS

Altamirano, Carlos. "El kirchnerismo es el hecho maldito del progresismo". Entrevista en Diario La Nación. Fecha: 18 de setiembre de 2011.

Beccaria, Luis. "Políticas para la reducción de la desigualdad". IV Foro del Bicentenario. Mimeo. Buenos Aires, 2008.

Beccaria, Alejandra y Danani, Claudia. "El proceso de reforma previsional argentina 2003-2008: instituciones y sentidos". X Jornadas Argentinas de Población. Mimeo. Catamarca: Asociación de Estudios de Población de la República Argentina, 2008.

Diario Clarín, varios números.

Diario La Nación, varios números.

Diario Página 12, varios números.

Jefatura de Gabinete de Ministros. "Memoria detallada del estado de la Nación 2003". Mimeo. 2003.

Fecha de ingreso: 29/11/2011 Fecha de aprobación: 10/02/2012 